\title{
The Effect of Vasopressin on Phosphate Transport in the Proximal Tubule of the Dog
}

\author{
SUNG-Feng WeN \\ From the Nephrology Program and the Department of Medicine, University of \\ Wisconsin Center for Health Sciences, Madison, Wisconsin 53706
}

\begin{abstract}
A B S T R A C T Recollection micropuncture study was performed in 11 thyroparathyroidectomized dogs during antidiuresis to determine the effect of continuous vasopressin infusion at $50 \mathrm{mU} / \mathrm{kg} / \mathrm{h}$ on proximal tubule phosphate and sodium transport. The animals were divided into two groups according to changes in mean arterial blood pressure. In the first group (five dogs) with increased blood pressure and glomerular filtration rate (GFR), mean proximal tubule fluid-to-plasma inulin ratio fell significantly from 1.69 to 1.53 , whereas it remained unchanged at 1.60 in the second group ( dogs) with no change in blood pressure. In contrast, mean proximal tubule fluid-to-plasma ultrafilterable phosphate ratio increased consistently in both groups, regardless of blood pressure changes. Since natriuresis as well as phosphaturia were observed in all animals, the sodium effect of vasopressin in the distal nephron must be mainly responsible for the natriuresis. It was concluded that vasopressin, when given in the doses employed, inhibits phosphate transport in the proximal tubule and sodium reabsorption in the distal nephron. An additional effect on proximal tubule sodium reabsorption appears to be related to the rise in blood pressure and GFR secondary to vasopressin administration.
\end{abstract}

\section{INTRODUCTION}

Although the antidiuretic effect of vasopressin is well known, attention has been centered recently on its natriuretic and phosphaturic effects when it is given in pharmacologic doses (1-3). Kurtzman and Rogers (2) administered large doses of vasopressin intravenously to the dog and demonstrated marked diuresis,

This work was presented in part at the National Meeting of the American Federation for Clinical Research, Atlantic City, N. J., April 28, 1973, and published in abstract form in Clin. Res. $21:$ 713. 1973.

Received for publication 12 September 1973 and in revised form 30 November 1973. natriuresis, and phosphaturia analogous to the effect of potent diuretics. Martinez-Maldonado, Eknoyan, and Suki (3) also showed unilateral natriuresis in the dog by direct intrarenal-artery injection of small doses of vasopressin as well as dibutyryl cyclic adenosine $3^{\prime}, 5^{\prime}$ monophosphate (cyclic AMP). ${ }^{1}$ Because of the concomitant phosphaturia, they concluded that vasopressin exerts natriuresis by stimulating the production of cyclic AMP in the proximal tubule of the kidney, thereby reducing its sodium and phosphate reabsorption. On the other hand, the available micropuncture studies in the literature (4-6) failed to demonstrate any effect of vasopressin on proximal tubule sodium transport in the animals undergoing water diuresis. Our present micropuncture study was undertaken to reexamine whether proximal tubule transport of sodium and phosphate could be altered in thyroparathyroidectomized (TPTX) dogs by administration of vasopressin in the doses frequently employed in experimental conditions. Our results indicate that the pharmacologic doses of vasopressin inhibit phosphate transport in the proximal tubule but that its effect on sodium transport appears to be related to changes in arterial blood pressure and glomerular filtration rate (GFR) associated with vasopressin administration.

\section{METHODS}

Recollection micropuncture study was performed in 11 mongrel dogs of either sex, weighing $12-20 \mathrm{~kg}$. All animals were maintained on Fromm Dog Meal (Federal Food, Inc., Thiensville, Wis.) containing $34 \mathrm{mmol}$ phosphate $/ 100 \mathrm{~g}$, and the average daily phosphate intake by these animals was appoximately $100 \mathrm{mmol} / \mathrm{day}$. The animals were thyroparathyroidectomized 3 days before the micropuncture experiments and calcium carbonate was added to the diet to

1 Abbreviations used in this paper: GFR, glomerular filtration rate; $\mathrm{PAH}$, para-aminohippurate; $\mathrm{TF} / \mathrm{P}_{\mathrm{In}}$, tubule fluid-to-plasma inulin ratio; $\mathrm{TF} / \mathrm{UF}_{\mathbf{P O}_{4}}$, tubule fluid-toplasma ultrafilterable phosphate ratio; TPTX, thyroparathyroidectomized; $\mathrm{TC}_{\mathrm{H}_{2} \mathrm{O}}$, free water reabsorption. 
TABLE I

Proximal Tubule Micropuncture Data

\begin{tabular}{|c|c|c|c|c|c|c|c|}
\hline $\begin{array}{l}\text { Exp. } \\
\text { groups }\end{array}$ & Dogs & $\begin{array}{l}\text { Exp. } \\
\text { phases }\end{array}$ & MBP & GFR & $\mathrm{TF} / \mathbf{P}_{\mathbf{I n}}$ & TF/UFPO4 & $(\mathrm{TF} / \mathrm{UF})_{\mathrm{PO}} /(\mathrm{TF} / \mathrm{P})_{\mathrm{In}}$ \\
\hline & & & $m m \mathrm{Hg}$ & $m l, m i n$ & & & \\
\hline \multirow[t]{2}{*}{ I } & $5(24)$ & Control & $127 \pm 4$ & $33.9 \pm 4.5$ & $1.69 \pm 0.05$ & $0.70 \pm 0.07$ & $0.42 \pm 0.04$ \\
\hline & & Vasopressin & $147 \pm 6 \ddagger$ & $44.2 \pm 6.9^{*}$ & $1.53 \pm 0.08 \ddagger$ & $0.89 \pm 0.09^{*}$ & $0.62 \pm 0.08^{*}$ \\
\hline \multirow[t]{2}{*}{ II } & $6(29)$ & Control & $130 \pm 8$ & $34.3 \pm 4.4$ & $1.60 \pm 0.10$ & $0.61 \pm 0.05$ & $0.39 \pm 0.04$ \\
\hline & & Vasopressin & $127 \pm 8$ & $35.7 \pm 5.0$ & $1.60 \pm 0.13$ & $0.80 \pm 0.04 \ddagger$ & $0.52 \pm 0.04 \ddagger$ \\
\hline
\end{tabular}

Values are mean $\pm \mathrm{SEM}$

Number in parentheses denotes that of tubule fluid samples.

$* P<0.05 ; \ddagger P<0.01$.

Abbreviations: $\mathrm{MBP}$, mean blood pressure; $\mathrm{TF} / \mathrm{P}_{\mathbf{I n}_{\mathbf{n}}}$, tubule fluid-to-plasma inulin ratio; $\mathrm{TF} / \mathrm{UF}_{\mathbf{P O}}$, tubule fluidto-plasma ultrafilterable phosphate ratio.

prevent the development of tetany. Water was allowed ad lib until the morning of micropuncture experiment.

Animals were prepared for micropuncture in a manner previously described (7). A femoral artery was cannulated for measurement of blood pressure and both ureters were catheterized for collection of urine. Recollection micropuncture study was carried out during the control phase of antidiuresis, which was followed by a second phase with continuous infusion of vasopressin (Pitressin, Parke, Davis \& Co., Detroit, Mich.) at $50 \mathrm{mU} / \mathrm{kg} / \mathrm{h} .45 \mathrm{~min}-1 \mathrm{~h}$ was allowed before the micropuncture was resumed in the second phase and fluid infusions were given at rates that would replace the urinary loss and avoid any volume expansion throughout the experiment. The micropuncture experiments were divided into two groups according to blood pressure responses after vasopressin administration. Group I consisted of five experiments in which mean arterial blood pressure increased by $14 \mathrm{~mm} \mathrm{Hg}$ or more, whereas in the remaining six experiments, group II, mean blood pressure either remained relatively unchanged or decreased slightly.

Standard clearance techniques were employed for 15-min collection periods. The plasma ultrafiltrate was obtained by centrifugation in a collodion bag (8) under optimal $\mathrm{pH}$ control. Tubule fluid was analyzed for inulin by the ultramicrofluorometric method (9), and for phosphate by a modification of the microcolorimetric method, with ascorbic acid as the reducing agent (10). Phosphate in the plasma, ultrafiltrate, and urine was determined by AutoAnalyzer method with stannous chloride-hydrazine (11), inulin and para-aminohippurate (PAH) by AutoAnalyzer methods (12) and sodium by flame photometry (Instrumentation Laboratory, Inc., Lexington, Mass.). The validity of control recollection for inulin and phosphate in TPTX dogs in our laboratory has previously been documented (7). Micropuncture and clearance data were analyzed statistically, with Student's $t$ test for paired comparison (13) of the mean values per animal between the two experimental phases.

\section{RESULTS}

After infusion of vasopressin at $50 \mathrm{mU} / \mathrm{kg} / \mathrm{h}$ in 11 TPTX dogs, mean arterial blood pressure increased in 5 dogs by $20 \pm 3 \mathrm{~mm} \mathrm{Hg}$, whereas the pressure remained unchanged in 6 before and after vasopressin. Mean GFR of the micropunctured kidney increased significantly in the first group by $10.3 \pm 2.6 \mathrm{ml} / \mathrm{min}$. In the second group, GFR increased in four and decreased in two dogs with the mean remaining unchanged $(P>0.7)$. Since the animals with increased mean blood pressure showed a response in proximal tubule sodium reabsorption different from those without increased blood pressure, micropuncture data for the two groups were considered separately. However, clearance data for all 11 experiments were pooled together, as no significant difference in the pattern of urinary electrolyte excretion between the two groups was observed.

Micropuncture data in the two groups of animals are summarized in Table I. In the first group with increased blood pressure, mean proximal tubule fluid-to-

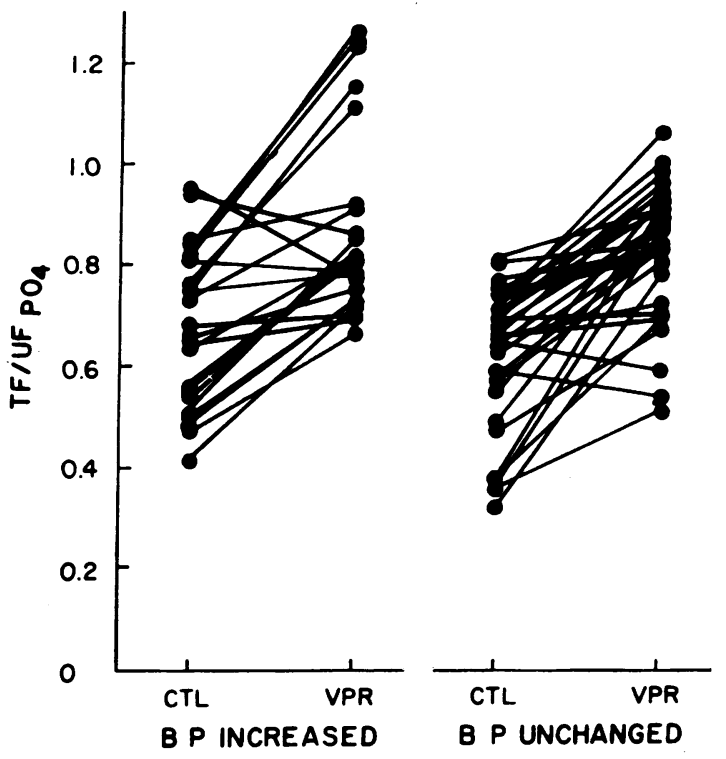

FIGURE 1 Individual proximal TF/UF phosphate ratios before (CTL) and after vasopressin (VPR) in the two groups. Lines connect paired values for the same experiment.

Vasopressin Effect on Phosphate Transport 
TABLE II

Mean Fractional Sodium and Phosphate Reabsorption by the Proximal Tubule for Each Experiment Before and After Vasopressin Administration

\begin{tabular}{|c|c|c|c|c|c|c|c|c|c|c|c|}
\hline \multirow{2}{*}{$\begin{array}{l}\text { Exp. } \\
\text { groups }\end{array}$} & \multirow[b]{2}{*}{ Dogs } & \multicolumn{2}{|c|}{ MBP } & \multicolumn{2}{|c|}{ GFR } & \multicolumn{3}{|c|}{$\mathrm{FR}_{\mathrm{Na}}$} & \multicolumn{3}{|c|}{$\mathrm{FR}_{\mathrm{PO} 4}$} \\
\hline & & C & E & C & $\mathrm{E}$ & C & E & $\Delta$ & C & E & $\Delta$ \\
\hline & & \multicolumn{2}{|c|}{$m m \mathrm{Hg}$} & \multicolumn{2}{|c|}{$m l / m i n$} & \multicolumn{3}{|c|}{$\%$} & \multicolumn{3}{|c|}{$\%$} \\
\hline \multirow[t]{5}{*}{ I } & 62 & 116 & 132 & 45.0 & 63.5 & 45 & 43 & -2 & 73 & 57 & -16 \\
\hline & 64 & 132 & 146 & 21.3 & 28.7 & 43 & 38 & -5 & 53 & 40 & -13 \\
\hline & 65 & 119 & 135 & 41.9 & 56.3 & 42 & 37 & -5 & 37 & 17 & -20 \\
\hline & 67 & 133 & 162 & 26.1 & 31.1 & 38 & 25 & -13 & 51 & 43 & -8 \\
\hline & 107 & 133 & 158 & 35.1 & 41.2 & 36 & 26 & -10 & 60 & 42 & -18 \\
\hline \multirow[t]{6}{*}{ II } & 66 & 105 & 97 & 38.6 & 26.6 & 40 & 38 & -2 & 58 & 43 & -15 \\
\hline & 69 & 161 & 159 & 43.3 & 31.5 & 21 & 23 & +2 & 50 & 37 & -13 \\
\hline & 110 & 136 & 136 & 18.5 & 27.4 & 41 & 41 & 0 & 71 & 49 & -22 \\
\hline & 111 & 126 & 121 & 34.9 & 43.3 & 35 & 35 & 0 & 72 & 61 & -11 \\
\hline & 112 & 116 & 119 & 46.2 & 57.3 & 50 & 53 & +3 & 65 & 58 & -7 \\
\hline & 115 & 137 & 132 & 24.2 & 28.0 & 28 & 22 & -6 & 48 & 39 & -9 \\
\hline
\end{tabular}

Abbreviations: C, control phase; E, experimental phase; FR, fractional reabsorption. Others as in Table I.

plasma $(\mathrm{TF} / \mathrm{P})$ inulin ratio fell significantly by $0.16 \pm$ 0.03 , while this value remained unchanged at 1.60 in the second group without blood pressure change. In contrast, mean proximal tubule fluid-to-plasma ultrafilterable (TF/UF) phosphate ratio increased significantly in both groups by $0.19 \pm 0.07$ and $0.19 \pm 0.04$, respectively. These changes are depicted in Fig. 1, in which the individual proximal TF/UF phosphate values before and after vasopressin are plotted. Mean fraction of filtered phosphate remaining in the late proximal tubule $\left[(\mathrm{TF} / \mathrm{UF})_{\mathbf{P o}_{4}} /(\mathrm{TF} / \mathrm{P})_{\mathrm{In}}\right]$ increased by $0.20 \pm 0.07$ and $0.13 \pm 0.02$ in the two groups. These observations indicate that, while the effect of vasopressin on proximal tubule sodium reabsorption was dependent on increase in blood pressure, fractional phosphate reabsorption in the proximal tubule was reduced by the action of vasopressin with or without blood pressure changes. These points are further demonstrated in Table II, in which the values for fractional proximal tubule reabsorption of sodium and phosphate in each experiment are shown. In group $I$, there were generally parallel changes in proximal tubule sodium and phosphate transport, while in group II fractional phosphate reabsorption was reduced without significant sodium changes in five out of six experiments, indicating dissociation of the two transports in the proximal tubule.

Clearance data of all 11 dogs before and after vasopressin administration are summarized in Table III. Mean urine flow increased slightly $(P<0.05)$, suggesting a small diuretic effect of vasopressin when given in pharmacologic doses during antidiuresis. Mean urine osmolality did not change significantly but mean free water reabsorption $\left(\mathrm{TC}_{\mathrm{H}_{2} \mathrm{O}}\right.$ ) increased slightly after vasopressin. Mean fractional excretion of sodium increased

TABLE III

Summary of Clearance Data in 11 TPTX Dogs

\begin{tabular}{|c|c|c|c|c|c|c|c|c|}
\hline $\begin{array}{l}\text { Exp. } \\
\text { phases }\end{array}$ & GFR & $\mathrm{C}_{\mathrm{PAH}}$ & UF $\mathrm{PO}_{4}$ & $\mathrm{v}$ & Uosm/kg & $\mathrm{TC}_{\mathrm{H} 2 \mathrm{O}}$ & $\mathrm{FE}_{\mathrm{Na}}$ & FEPO4 \\
\hline & $m l / m i n$ & $\mathrm{ml} / \mathrm{min}$ & $\mathrm{mmol} / \mathrm{liter}$ & $\mathrm{ml} / \mathrm{min}$ & $\mathrm{mosmol} / \mathrm{kg}$ & $m l / \min$ & $\%$ & $\%$ \\
\hline \multirow[t]{2}{*}{ Control } & 34.1 & 95.8 & 2.08 & 0.86 & 501 & 0.14 & 1.35 & 2.45 \\
\hline & \pm 3.0 & \pm 11.5 & \pm 0.22 & \pm 0.36 & \pm 65 & \pm 0.18 & \pm 0.41 & \pm 0.65 \\
\hline \multirow[t]{2}{*}{ Vasopressin } & 39.5 & 99.0 & 2.19 & $1.26^{*}$ & 533 & $0.31^{*}$ & $2.61^{*}$ & $11.90 \ddagger$ \\
\hline & \pm 4.1 & \pm 12.0 & \pm 0.19 & \pm 0.43 & \pm 68 & \pm 0.19 & \pm 0.81 & \pm 2.72 \\
\hline
\end{tabular}

Values are mean $\pm \mathrm{SEM}$.

${ }^{*} P<0.05 ; \ddagger P<0.01$.

Abbreviations: $\mathrm{C}_{\mathrm{PAH}}$, para-aminohippurate clearance; $\mathrm{V}$, urine flow; $\mathrm{U}_{\mathrm{osm} / \mathrm{kg}}$, urine osmolality; $\mathrm{TC}_{\mathrm{H}_{20} \mathrm{O}}$, free water reabsorption; FE, fractional excretion; others as in Table I. 
by $1.3 \pm 0.4 \%$ and that of phosphate by $9.5 \pm 2.4 \%$, indicating that a modest natriuresis and moderate phosphaturia occurred after vasopressin, regardless of changes in blood pressure.

\section{DISCUSSION}

Our present micropuncture study showed that vasopressin, when given in the doses employed, effects phosphaturia by inhibition of fractional proximal tubule phosphate reabsorption. This effect was independent of changes in circulating parathyroid hormone level, systemic arterial blood pressure, or GFR, since these parameters were all relatively unchanged in the second group of animals studied. In contrast, reduction in fractional proximal tubule sodium reabsorption was observed only in the first group with increased arterial blood pressure and GFR. The reasons for the variable blood pressure changes after vasopressin are unknown, but they may represent differences in individual responsiveness to the given dose of vasopressin. An inhibitory effect of vasopressin on proximal tubule sodium reabsorption has not been demonstrated previously (46 ). The earlier micropuncture studies were carried out because there may be stimulation of sodium transport by vasopressin as suggested by toad bladder studies (14), but such a stimulatory effect could not be shown except in the isolated collecting tubules (15). It is not clear whether the failure to demonstrate proximal tubule effects of vasopressin by others was due to the use of hydrated animals undergoing water diuresis in their studies, as compared to antidiuretic animals used in ours. Also, their animals were not divided according to blood pressure changes, which were apparently responsible for our data. It has been demonstrated that acute increase in arterial blood pressure may reduce proximal tubule sodium reabsorption, presumably by increasing hydrostatic pressure in the peritubular capillaries (16). In addition, increased GFR in the first group of our study may also have contributed to the observed reduction in fractional sodium reabsorption in the proximal tubule. In contrast to the dependence of changes in proximal tubule sodium transport on elevated blood pressure, natriuresis occurred in all animals, regardless of blood pressure changes. This strongly suggests that a distal effect of vasopressin on sodium transport was mainly responsible for the observed natriuresis. Indeed, such an inhibitory effect of vasopressin on distal nephron has been demonstrated by Antoniou, Burke, Robinson, and Clapp (6).

In our study, mean proximal TF/UF phosphate during antidiuresis in TPTX dogs was relatively high at $0.6-0.7$, which was probably related to high phosphate intake (7), since administration of aluminum hydroxide to reduce intestinal phosphate absorption resulted in a lower mean proximal TF/UF phosphate of $0.45 .^{2}$ After administration of vasopressin, the magnitude of changes in fractional phosphate reabsorption in the proximal tubule was similar to or greater than that at the final urine level, suggesting that the phosphaturic effect of vasopressin could be accounted for mainly by its action in the proximal tubule.

The mechanism by which vasopressin exerts its effect on proximal tubule phosphate transport is unknown. Martinez-Maldonado et al. (3) injected dibutyryl cyclic AMP to the renal artery and demonstrated phosphaturia similar to that caused by vasopressin. Since vasopressin is known to stimulate adenyl cyclase to increase the production of cyclic AMP, they postulated that natriuretic and phosphaturic effects of vasopressin may be mediated through the cyclic AMP system in the proximal tubule cells. Our finding of reduced phosphate transport in the proximal tubule with vasopressin as well as the findings of others with dibutyryl cyclic AMP (17) are consistent with this concept. However, absence of changes in proximal tubule sodium transport after vasopressin when systemic blood pressure was unchanged suggests a slightly different response of the proximal tubule transport to vasopressin, as compared with that of cyclic AMP or parathyroid hormone (7, 17). This dissociation of sodium and phosphate transport in the proximal tubule has also been demonstrated in saline-loaded dogs after alterations of parathyroid hormone levels (7). The possibility of a release by vasopressin of extrarenal phosphaturic factors other than parathyroid hormone also cannot be excluded, as Dimond and Buckalew (18) showed suggestive evidence of an extrarenal natriuretic factor after vasopressin administration. Whatever the mechanism may be, the fact that significant phosphaturia and natriuresis can be induced by administration of vasopressin in the doses frequently employed in experimental conditions indicates that such pharmacologic effects of vasopressin should be taken into consideration when phosphate and sodium transport is studied under such conditions.

\section{ACKNOWLEDGMENTS}

The author is grateful to Mrs. Linda Solen, Mrs. Kathleen Zweifel, and Mr. Rick Hart for their expert technical assistance.

This work was supported by a research grant (AM 15512-02) from the National Institute of Arthritis, Metabolism and Digestive Diseases, and by research funds from the University of Wisconsin Medical School and Graduate School.

\footnotetext{
${ }^{2}$ Unpublished observation.
}

Vasopressin Effect on Phosphate Transport 


\section{REFER ENCES}

1. Humphreys, M. H., R. M. Friedler, and L. E. Earley. 1970. Natriuresis produced by vasopressin or hemorrhage during water diuresis in the dog. Am. J. Physiol. 219: 658.

2. Kurtzman, N. A., and P. W. Rogers. 1972. The diuretic effect of anti-diuretic hormone. Clin. Res. 20:600.

3. Martinez-Maldonado, M., G. Eknoyan, and W. N. Suki. 1971. Natriuretic effects of vasopressin and cyclic AMP : possible site of action in the nephron. Am. J. Physiol. 220: 2013.

4. Davis, B. B., F. G. Knox, and R. W. Berliner. 1967. Effect of vasopressin on proximal tubule sodium reabsorption in the dog. Am. J. Physiol. 212: 1361.

5. Schnermann, J., H. Valtin, K. Thurau, W. Nagel, M. Horster, H. Fischbach, M. Wahl, and G. Liebau. 1969. Micropuncture studies on the influence of antidiuretic hormone on tubular fluid reabsorption in rats with hereditary hypothalamic diabetes insipidus. Pfiügers Arch. Eur. J. Physiol. 306: 103.

6. Antoniou, L. D., T. J. Burke, R. R. Robinson, and J. R. Clapp. 1973. Vasopressin-related alterations of sodium reabsorption in the loop of Henle. Kidney Int. $3: 6$.

7. Wen, S. F. 1974. Micropuncture studies of phosphate transport in the proximal tubule of the dog: the relationship to sodium reabsorption. J. Clin. Invest. 53: 143.

8. Osmun, J. R. 1967. Total and ultrafilterable calcium and magnesium in human plasma: improved method and normal values. Am. J. Med. Tech. 33: 448.
9. Vurek, G. G., and S. E. Pegram. 1966. Fluorometric method for the determination of nanogram quantities of inulin. Anal. Biochem. 16: 409.

10. Chen, P. S., Jr., T. Y. Toribara, and H. Warner. 1956. Microdetermination of phosphorus. Anal. Chem. 28: 1756.

11. Kraml, M. 1966. A semi-automated determination of phospholipids. Clin. Chim. Acta. 13: 442.

12. Steele, T. H. 1969. A modified semi-automated resorcinol method for the determination of inulin. Clin. Chem. 15: 1072.

13. Adler, H. L., and E. B. Roessler. 1962. Introduction to Probability and Statistics. W. H. Freeman \& Company, San Francisco, Calif. 2nd edition. 132.

14. Leaf, A., J. Anderson, and L. P. Page. 1958. Active sodium transport by the isolated toad bladder. J. Gen. Physiol. 41: 657.

15. Helman, S. I., J. J. Grantham, and M. B. Burg. 1971. Effect of vasopressin on electrical resistance of renal collecting tubules. Am. J. Physiol. 220: 1825.

16. Koch, K. M., H. S. Aynedjian, and N. Bank. 1968. Effect of acute hypertension on sodium reabsorption by the proximal tubule. J. Clin. Invest. 47: 1696.

17. Agus, A. S., J. B. Puschett, D. Senesky, and M. Goldberg. 1971. Mode of action of parathyroid hormone and cyclic adenosine $3^{\prime}, 5^{\prime}$-monophosphate on renal tubule phosphate reabsorption in the dog. J. Clin. Invest. 50: 617 .

18. Dimond, K. A., and V. M. Buckalew, Jr. 1973. Association of vasopressin natriuresis with a humoral sodium transport inhibitor. Clin. Res. 21: 684. 